\title{
AMCoR
}

Asahikawa Medical University Repository http://amcor.asahikawa-med.ac.jp/

Journal of cellular biochemistry (2012.Oct) 23:.

Tumor necrosis factor- $\alpha$ promotes bile ductular transdifferentiation of mature rat hepatocytes in vitro

Nishikawa Yuji, Sone Masayuki, Nagahama Yasuharu, Kumagai Eriko, Doi Yuko, Omori Yasufumi, Yoshioka Toshiaki, Tokairin Takuo, Yoshida Masayuki, Yamamoto Yohei, Ito Akihiko, Sugiyama Toshihiro, Enomoto Katsuhiko 


\section{Tumor necrosis factor- $\alpha$ promotes bile ductular transdifferentiation of mature rat hepatocytes in vitro}

Yuji Nishikawa, ${ }^{1 *}$ Masayuki Sone, ${ }^{2,3}$ Yasuharu Nagahama, ${ }^{1,2}$ Eriko Kumagai, ${ }^{3}$ Yuko Doi, ${ }^{4}$ Yasufumi Omori, ${ }^{3}$ Toshiaki Yoshioka, ${ }^{3}$ Takuo Tokairin, ${ }^{3}$ Masayuki Yoshida, ${ }^{3}$ Yohei Yamamoto, ${ }^{3}$ Akihiko Ito, ${ }^{5}$ Toshihiro Sugiyama, ${ }^{6}$ and Katsuhiko Enomoto ${ }^{3}$

${ }^{1}$ Division of Tumor Pathology, Department of Pathology, Asahikawa Medical University, Higashi 2-1-1-1 Midorigaoka, Asahikawa, Hokkaido 078-8510, Japan

${ }^{2}$ Fujii Memorial Research Institute, Otsuka Pharmaceutical Co. Ltd., 1-11-1 Karasaki, Otsu, Shiga 520-0106, Japan

${ }^{3}$ Department of Molecular Pathology and Tumor Pathology, Akita University Graduate School of Medicine, 1-1-1 Hondo, Akita 010-8543, Japan

${ }^{4}$ Central Research Laboratory, Akita University Graduate School of Medicine, 1-1-1 Hondo, Akita 010-8543, Japan

${ }^{5}$ Department of Pathology, Kinki University Faculty of Medicine, Ohno Higashi 377-2, Sayama, Osaka 589-8511, Japan

${ }^{6}$ Department of Biochemistry, Akita University Graduate School of Medicine, 1-1-1 Hondo, Akita 010-8543, Japan 
*Correspondence to: Yuji Nishikawa, Division of Tumor Pathology, Department of Pathology, Asahikawa Medical University, Higashi 2-1-1-1 Midorigaoka, Asahikawa, Hokkaido 078-8510, Japan. E-mail: nishikwa@asahikawa-med.ac.jp.

Running head: Promotion of ductular metaplasia by TNF- $\alpha$

Key words:

\section{- Ductular reaction}

- Transdifferentiation

- Tumor necrosis factor- $\alpha$

- Liver fibrosis

- Hepatocytes

- Bile duct cells

- JNK-c-Jun pathway

Total number of text figures: 8 ; table: 0

Supported by the Ministry of Education, Culture, Sports, Science and Technology of Japan (\#13670204, \#16590303, and \#18590362) 


\section{Abstract}

We previously showed that mature hepatocytes could transdifferentiate into bile ductular cells when placed in a collagen-rich microenvironment. To explore the mechanism of transdifferentiation, we examined whether inflammatory cytokines affected the phenotype of hepatocytes in a three-dimensional culture system. Spheroidal aggregates of rat hepatocytes were embedded within a type I collagen gel matrix and cultured in the presence of various cytokines. In the control, hepatocytes gradually lost expression of albumin, tyrosine aminotransferase, and hepatocyte nuclear factor (HNF)- $4 \alpha$, while aberrantly expressed bile ductular markers, including cytokeratin 19 (CK 19) and spermatogenic immunoglobulin superfamily (SgIGSF). Among the cytokines examined, tumor necrosis factor (TNF)- $\alpha$ inhibited expression of albumin and HNF-4 $\alpha$, both at mRNA and protein levels. After culturing for 2 weeks with TNF- $\alpha$, hepatocytic spheroids were transformed into extensively branching tubular structures composed of CK 19- and SgIGSF-positive small cuboidal cells. These cells responded to secretin with an increase in secretion and expressed functional bile duct markers. TNF- $\alpha$ also induced the phosphorylation of Jun N-terminal kinase (JNK) and c-Jun, and the morphogenesis was inhibited by SP600125, a specific JNK inhibitor.

Furthermore, in chronic rat liver injury induced by $\mathrm{CCl}_{4}$, ductular reaction in the centrilobular area demonstrated strong nuclear staining of phosphorylated c-Jun. Our results demonstrate that TNF- $\alpha$ promotes the ductular transdifferentiation of hepatocytes and suggest a role of TNF- $\alpha$ in the pathogenesis of ductular reaction. 


\section{Introduction}

Irregular ductular structures increase in various chronic liver diseases, including chronic hepatitis and cirrhosis (Desmet et al., 1995). The tissue reaction is called ductular reaction (Alvaro et al., 2007; Roskams et al., 2004) and it appears to be one of the factors that deteriorate liver function. This reaction gradually replaces the hepatic parenchyma and causes a gradual decrease in mature hepatocytes in the hepatic lobules or regenerative nodules. The origin of the increased bile ductules has been a matter of controversy. The cellular changes might be due to hepatic stem/progenitor cell activation, proliferation of preexisting cholangiocytes, or ductular metaplasia of mature hepatocytes (Alvaro et al., 2007; Roskams et al., 2004). While most investigators embrace the notion that the ductular reaction represents regenerative proliferation of bipotential hepatic stem/progenitor cells (Richardson et al., 2007; Roskams, 2003), there is no definitive evidence for this. Although it has been postulated that the hepatocytic phenotype is fixed once the cells are terminally differentiated, we and other investigators have demonstrated that hepatocytes are able to transdifferentiate into bile ductule/duct-like cells (Block et al., 1996; Michalopoulos et al., 2005; Michalopoulos et al., 2002; Nishikawa et al., 2005; Nishikawa et al., 1996). We reported that mature hepatocytes could be differentiated into bile ductular cells when cultured within a type I collagen gel matrix in the presence of insulin and epidermal growth factor (EGF) or hepatocyte growth factor (Nishikawa et al., 1996). Because the change of phenotype was not accompanied by the expression of hepatoblastic markers, such as delta-like and $\alpha$-fetoprotein, we interpreted this phenomenon as transdifferentiation, rather than dedifferentiation (Nishikawa et al., 2005). 
These studies demonstrated the phenotypic plasticity of mature hepatocytes and suggested that bile ductular transdifferentiation might be involved in ductular reaction.

Ductular reaction is typically seen in liver diseases associated with increased deposition of collagenous matrices produced by activated hepatic stellate cells (HSCs) (Clouston et al., 2005; Richardson et al., 2007). In such liver diseases, Kupffer cells are also activated and produce various inflammatory cytokines, such as tumor necrosis factor- $\alpha$ (TNF- $\alpha$ ), which is thought to play important pathogenetic roles (Bradham et al., 1998; Tacke et al., 2009). In fact, several anti-TNF- $\alpha$ therapies are effective in ameliorating chronic liver diseases in humans (Tilg et al., 2006) and rodents (Bahcecioglu et al., 2008; Iimuro et al., 1997; Li et al., 2003). Although the deleterious effects of TNF- $\alpha$ are usually ascribed to its pro-inflammatory actions through a modulation of non-parenchymal cells and immune cells, it could also directly affect hepatocytes. The effects of TNF- $\alpha$ on inducing proliferation and affecting apoptosis in hepatocytes have been extensively studied (Diehl et al., 1994; Leist et al., 1995; Rolfe et al., 1997). The knockout of TNF- $\alpha$ receptor type I in mice inhibits normal liver regeneration after partial hepatectomy (Yamada et al., 1997; Yamada et al., 1998) or $\mathrm{CCl}_{4}$ injury (Yamada and Fausto, 1998). However, TNF- $\alpha$ also decreases albumin expression in mature hepatocytes (Brenner et al., 1990) and suppresses hepatocytic maturation of hepatoblasts (Kamiya and Gonzalez, 2004), suggesting that it has negative effects on the differentiation of hepatocytes. Thus, it is possible that TNF- $\alpha$ alters hepatocyte differentiation in liver diseases.

To explore soluble factors that facilitate the ductular metaplasia of hepatocytes, we studied the effects of several cytokines that could be produced and secreted by Kupffer cells in 
a three-dimensional culture system using type I collagen gel. We found that TNF- $\alpha$ uniquely stimulated branching morphogenesis associated with the expression of bile duct/ductular markers, including cytokeratin 19 (CK 19). We further examined the long-term effects of TNF- $\alpha$ on ductular transdifferentiation and the possible cellular mechanisms of its action. Our results suggest that TNF- $\alpha$ might suppress the differentiation status of hepatocytes and stimulate their transformation into bile ductular cells, thereby contributing to the functional deterioration seen in chronic liver diseases.

\section{Materials and Methods}

\section{Isolation and culture of rat hepatocytes}

Hepatocytes from adult male F344 or Alb-DsRed2 transgenic rats(Sato et al., 2003) (10-20 weeks old) were isolated using the two-step collagenase perfusion method, followed by repeated low-speed centrifugation at $70 \mathrm{~g}$. Alb-DsRed2 rats, in which cells express DsRed2 fluorescence under the control of the albumin enhancer/promoter, were used to monitor the level of albumin gene expression in cultured hepatocytes. The protocols for animal experimentation were approved by the Animal Research Committee, Akita University. All animal experiments adhered to the criteria outlined in the Guide for the Care and Use of Laboratory Animals prepared by the National Academy of Sciences and published by the National Institutes of Health (NIH publication 86-23 revised 1985).

Isolated hepatocytes were plated onto positively charged plastic dishes (Primaria; Becton-Dickinson, Franklin Lakes, NJ) to form spheroidal aggregates. Cells were cultured in 
serum-free Williams' Medium E supplemented with $10 \mathrm{mM}$ nicotinamide, $10 \mathrm{ng} / \mathrm{ml}$ mouse EGF (Roche Diagnostics, Mannheim, Germany), and 10 $0^{-7} \mathrm{M}$ insulin (Sigma Chemical Company, Saint Louis, MO). After 5 days, spheroidal aggregates of hepatocytes were harvested and used for three-dimensional cultures.

Three-dimensional cultures of hepatocytic spheroids within the collagen gel matrix were performed using a type I collagen solution (Cellmatrix type I-A; Nitta Gelatin, Osaka, Japan) as described previously (Nishikawa et al., 1996). After being embedded within the gel, spheroidal aggregates were cultured in Williams' Medium E supplemented with $10 \mathrm{mM}$ nicotinamide and 10\% FBS (standard medium) with insulin $\left(10^{-7} \mathrm{M}\right)$ and EGF (10 ng/ml). Various cytokines (interleukin [IL]-1 $\alpha$, IL-1 $\beta$, IL-6, and TNF- $\alpha$ ] were added to the medium at $10 \mathrm{ng} / \mathrm{ml}$ and the effects on morphogenesis and differentiation were examined. Half of the medium was removed and replenished with the same amount of fresh medium at 2-day or 3-day intervals. A specific JNK inhibitor (SP600125; Calbiochem, San Diego, CA) was also added to the medium. In the experiments using Alb-DsRed2 transgenic rats, fluorescence intensity was monitored with a fluorescent plate reader (Cytofluor, PerSeption). DsRed2 fluorescence was excited at $530 \mathrm{~nm}$, and emissions were measured above $620 \mathrm{~nm}$.

In some experiments, fluorescein diacetate (Sigma) was added to the culture medium to delineate lumen structures formed by cultured hepatocytes. In our preliminary studies, the excretion of fluorescent material by cultured hepatocytes did not occur in the absence of dexamethasone. Cells were treated with $1 \mu \mathrm{M}$ dexamethasone 7 days prior to the addition of fluorescein diacetate. Furthermore, human synthetic secretin (Sigma) was added to the 
medium to test the secretory response of the cultured cells.

To observe the structures formed by cultured hepatocytes within the matrices, the gels were fixed in $10 \%$ buffered formalin, embedded in paraffin, sectioned, and stained with hematoxylin and eosin. To visualize the ultrastructures, cells were fixed with $2.5 \%$ glutaraldehyde and 1\% osmium tetroxide, and embedded in Epon resin. Ultrathin sections were stained with uranylate and lead and observed under an electron microscope (JEOL, Tokyo, Japan).

\section{Western blot analysis}

The cell-containing gels were washed with PBS and homogenized in a lysis buffer (1\% Triton X-100, 1\% sodium deoxycholate, $0.1 \%$ SDS, $158 \mathrm{mM}$ sodium chloride in $10 \mathrm{mM}$ Tris-HCl buffer; $\mathrm{pH}$ 7.5) containing a protease inhibitor cocktail. In a preparatory experiment, we confirmed that polymerized collagen in the gel was almost insoluble and did not interfere with the further analysis. Protein samples were also prepared from the non-parenchymal cells, which were present in the supernatant after the first low-speed centrifugation during hepatocyte isolation, and undigested portal tissues. Samples (40 $\mu \mathrm{g}$ protein per lane) were subjected to SDS-PAGE using $10 \%$ polyacrylamide gel, and then transferred to PVDF membranes. The primary antibodies used were anti-albumin (rat-specific, Nordic Immunological Laboratories, Tilburg, Netherlands), anti-HNF-4 $\alpha$ (K9218, Perseus Proteomics, Tokyo, Japan), anti-CK 8 (American Research Products, Belmont, MA), anti-CK 19 (Amersham-Pharmacia Biotech UK, Buckinghamshire, England), anti-spermatogenic 
immunoglobulin superfamily (SgIGSF) (Ito et al., 2007), anti-occludin (Zymed Laboratories, South San Francisco, CA), anti-ZO-1 (Zymed Laboratories, South San Francisco, CA), anti-integrin $\beta 1$ (Santa Cruz Biotechnology), anti-phospho-ERK (Santa Cruz Biotechnology), anti- $\beta$-actin (Novus Biologicals, Littleton, CO), anti-phospho-Akt (Cell Signaling Technology), anti-phospho-p38 MAPK (Cell Signaling Technology), anti-phospho-Stat3 (Cell Signaling Technology), anti-phospho-p65 (Ser536; Cell Signaling Technology), anti-phospho-JNK (Cell Signaling Technology), and anti-phospho-c-Jun (Cell Signaling Technology). Detection was performed with enhanced chemiluminescence reagents (Amersham-Pharmacia Biotech, UK). Integrin $\beta 1$, whose expression was found to be relatively constant in cultured hepatocytes, was used as a reference protein, together with $\beta$-actin. For quantification of protein expression, densitometry of blots was performed using ImageJ 1.46a, and statistical comparisons were performed using Student's $t$ test.

\section{Reverse-transcriptase polymerase chain reaction (RT-PCR)}

Total RNA from hepatocytes and portal tissues was prepared using TRIzol reagent (Life Technologies). We also performed quantitative RT-PCR analysis by the $\Delta \Delta \mathrm{Ct}$ method using a LightCycler 480 SYBR Green I Master (Roche Diagnostics, Mannheim, Germany) and an LightCycler 480 Instrument (Roche Diagnostics). Each RNA sample (50 ng) was reverse-transcribed by using Transcriptor First Strand cDNA Synthesis Kit (Roche Diagnostics). Following the activation of FastStart Taq DNA polymerase at $95^{\circ} \mathrm{C}$ for 5 minutes, the cDNA was amplified with 40 cycles of a three-step PCR $\left(95^{\circ} \mathrm{C}\right.$ for 10 seconds, 
$60^{\circ} \mathrm{C}$ for 10 seconds, $72^{\circ} \mathrm{C}$ for 10 seconds). Reactions were done in duplicate and the mRNA levels were normalized using glyceraldehyde 3-phosphate dehydrogenase (GAPDH) as a housekeeping gene.

For conventional RT-PCR analysis, a one-step RT-PCR kit (TaKaRa) was used for the reaction, in which RNA $(0.5 \mu \mathrm{g})$ was reverse transcribed using AMV reverse transcriptase for $30 \mathrm{~min}$ and then amplified for 25 cycles of 95,60 , and $72^{\circ} \mathrm{C}$ for 30,30 , and $90 \mathrm{~s}$, respectively.

The specific primers used and the expected fragment sizes were as follows: albumin: forward 5'-TTGCCAAGTACATGTGTGAG-3', reverse 5'-GGTTCTTCTACAAGAGGCTG-3', 373 bp; tyrosine transaminase (TAT): forward 5'-ACAGCGTGTCTTGTTGTCAAC-3', reverse 5'-TAAGGTACATGGCTCCAGAAG-3', 499 bp: hepatocyte nuclear factor (HNF)-4 $\alpha$ : forward 5'-GACATGGACATGGCTGACTAC-3', reverse 5'-GACGGCTTCTTTCTTCATGCC-3', 366 bp; CK 19: forward 5'GACTTCCTATAGCTATCGCC-3', reverse 5'- AGTAGGAGGCGAGGCGATCG-3', 290 bp; HNF-6: forward 5'-CAGCCTGCAAAAGGAAAGAGC-3', reverse 5'-TCCGTGGTTCTTCCTTCATGC-3', 311 bp; peroxisome proliferator-activated receptor $\gamma$ coactivator 1(PGC-1): forward, 5'-TGCAGCCAAGACTCTGTATGG-3', reverse, 5'-GTCTCCATCTGTCAGTGCATC-3', 327 bp; cystic fibrosis transmembrane conductance regulator (CFTR): forward 5'-CTAACTGAGACCTTACGCAGG-3', reverse 5'-CAGACTGTCTTCTTCTGCCTG-3', 300 bp; aquaporin (AQP)-1: forward 5'-GGAGATGAAGCCCAAATAGAG-3', reverse 
5'-CAGGAAACAGAAAGAAAGACAG-3', 202 bp; AQP 4: forward 5'-AGCATGAATCCAGCTCGATCC-3', reverse 5'-TCCTTCCCCTTCTTCTCGTCTC-3', 311 bp; AQP 8: forward 5'-AAGACCATGCTGCTAATTCC-3', reverse 5'-TCCACAATGACAGAGAAACC-3', 275 bp; AQP 9: forward 5'-TGTTGTCATTAGCCTCCTGATC-3', reverse 5'-TGAAGAAAGAACTGGATGAACG-3', 356 bp; albumin: forward 5'-TTGCCAAGTACATGTGTGAG-3', reverse 5'-GGTTCTTCTACAAGAGGCTG-3', 373 bp; tyrosine transaminase (TAT): forward 5'-ACAGCGTGTCTTGTTGTCAAC-3', reverse 5'-TAAGGTACATGGCTCCAGAAG-3', 499 bp; CK 19: forward 5'- GACTTCCTATAGCTATCGCC-3', reverse 5'TCTGGTACCAGTCGCGAATC-3', bp; GAPDH: forward 5'-ACCACAGTCCATGCCATCAC-3', reverse 5'-TCCACCACCCTGTTGCTGTA-3', 452 bp.

\section{Induction of liver fibrosis in rats}

To induce chronic liver injury with fibrosis and ductular reaction, a 1:1 mixture of $\mathrm{CCl}_{4}$ and olive oil was administered to male F344 rats (7 weeks old) by gavage at a dose of $2 \mathrm{ml} / \mathrm{kg}$ twice per week for 8 weeks. The animals were sacrificed, and the liver tissues were fixed in $10 \%$ buffered formalin, paraffin-embedded, and sectioned.

\section{Immunohistochemistry}

Paraffin sections were deparaffinized and treated with Target Retrieval Solution (DAKO) at 
$95{ }^{\circ} \mathrm{C}$ for 40 minutes. Immunocytochemistry was performed using the LSAB kit for rat tissues (DAKO). The following primary antibodies were used: anti-CK 19 (mouse monoclonal; 1:200 dilution; Amersham-Pharmacia Biotech UK), anti-SgIGSF, and anti-phospho-c-Jun.

\section{Results}

\section{TNF- $\alpha$ facilitates bile ductular transdifferentiation of hepatocytes within a collagen gel}

\section{matrix}

We first examined the effects of various cytokines (IL-1 $\alpha$, IL-1 $\beta$, IL-6, and TNF- $\alpha$ ) that are known to be secreted principally by Kupffer cells, on DsRed2 fluorescence, which reflects albumin expression, in hepatocytes cultured in a three-dimensional collagen gel matrix. The hepatocytic spheroids cultured on Primaria dishes for 5 days demonstrated a high level of fluorescence intensity, but it gradually decreased in association with branching morphogenesis within the collagen gel (Fig. 1A). The branching morphogenesis was enhanced by IL-6 and TNF- $\alpha$, with the appearance of more complex and finer branches in the presence of TNF- $\alpha$ (Fig. 1A), while IL-1 $\alpha$ and IL-1 $\beta$ inhibited branching morphogenesis and induced cyst formation inside the aggregates (data not shown). DsRed2 fluorescence was well maintained in the presence of IL-6, but markedly reduced by TNF- $\alpha$ (Fig. 1A). Quantitative analysis using a fluorescence plate reader confirmed the contrasting effects of IL-6 and TNF- $\alpha$ on DsRed2 fluorescence (Fig. 1B). While IL-1 $\alpha$ and IL-1 $\beta$ transiently increased fluorescence after 1 day, they inhibited it thereafter (Fig. 1B). TNF-like weak inducer of apoptosis (TWEAK), which induces oval cell proliferation in mice (Jakubowski et al., 2005), was also tested. Although it 
induced dendritic morphogenesis, the effect was much weaker than from TNF- $\alpha$, even at 100 $\mathrm{ng} / \mathrm{ml}$ (data not shown).

TNF- $\alpha$ suppresses the expression of markers of hepatocytes, but does not affect those of bile ductular cells and cell adhesion molecules in hepatocytes within a collagen gel matrix

We examined the effect of TNF- $\alpha$ on the expression of various differentiation markers for hepatocytes and bile ductular cells with Western blotting and RT-PCR. Hepatocytes prior to culture strongly expressed albumin, but they did not express CK 19 (Fig. 2A, B). The protein expression of albumin and HNF-4 $\alpha$, a hepatocyte-specific transcription factor, was decreased in culture, and the decline was facilitated by TNF- $\alpha$ (Fig. 2A, B). Compatible with these observations, the gene expression of albumin and HNF- $4 \alpha$, as well as TAT, was decreased in culture, especially in the presence of TNF- $\alpha$ (Fig. 3). The protein expression of CK 8 was low in hepatocytes, but it was markedly increased in culture (Fig. 2A, B). There was aberrant expression of CK 19, a bile duct-specific cytokeratin, both at protein and mRNA levels (Figs. 2 and 3). Furthermore, SgIGSF protein, which is known to be present in immature bile ducts(Ito et al., 2007), was expressed in cultured hepatocytes (Fig. 2A). Consistent with the appearance of the bile duct markers, an increase of the mRNA of HNF-6, an essential transcription factor for the development of bile ducts (Clotman et al., 2002), was noted (Fig. 3). TNF- $\alpha$ did not affect protein expression of CK 8, CK 19, and SgIGSF (Figs. 2A, B). While TNF- $\alpha$ slightly facilitated the CK 19 mRNA expression during the early period of collagen gel 
culture, it did not change the level of HNF-6 mRNA (Fig. 3). Interestingly, TNF- $\alpha$ specifically enhanced the mRNA expression of PGC-1, a coactivator of many transcription factors, such as HNF-4 $\alpha$ and farnesoid X receptor (FXR) (Fig. 3).

While the protein expression of occludin and ZO-1 was enhanced in culture, TNF- $\alpha$ did not consistently influence their expression (Fig. 2). The mRNA expression of E-cadherin was increased in culture, without being significantly affected by TNF- $\alpha$ (data not shown). The mRNAs of the receptors for TNF- $\alpha$ (TNFR1, TNFR2) were expressed in hepatocytes, and their expression levels remained constant during culture and were not affected by TNF- $\alpha$ (data not shown).

\section{TNF- $\alpha$ enhances branching tubular morphogenesis of cultured hepatocytes}

Consistent with our previous report, hepatocytic spheroids underwent branching morphogenesis when cultured within the collagen gel (Fig. 4A). The morphogenesis was markedly enhanced by TNF- $\alpha$, and the branching cellular processes extended from each spheroid into the gel, forming intricate networks that obscured the original spheroid aggregates after 3 weeks (Fig. 4A). Analysis of sections taken from these branching structures revealed that they were composed of ductules that were immunocytochemically positive for CK 19 and SgIGSF (Fig. 4B). Despite the similar levels of protein expression in Western blots, the TNF- $\alpha$-treated cells demonstrated higher staining intensity as compared with control cells (Fig. 4B). Ultrastructurally, these tubular structures were surrounded by basement membranes (Fig. 4C). 


\section{The ductular structures induced by TNF- $\alpha$ show secretory properties}

We next determined whether the ductules formed within the collagen gel had a secretory capacity. Fluorescein diacetate, which is taken up, metabolized, and secreted by glandular cells, was added to the cultures. In the presence of dexamethasone, the dye was secreted into the lumens within 30 minutes (Fig. 5A). Furthermore, secretin, which acts on bile ductal cells and facilitates their secretory activity, rapidly dilated the lumens (Fig. 5B).

We also examined the gene expression of proteins involved in the secretory function of bile duct cells. Normal bile duct cells express CFTR, which regulates the extracellular excretion of chloride ion. CFTR mRNA was detected in the portal tissue containing bile ducts, but not in hepatocytes (Fig. 5C). However, CFTR mRNA was detected in hepatocytes cultured within the collagen gel for 3 weeks (Fig. 5C). The expression was augmented by TNF- $\alpha$, either in the absence or in the presence of dexamethasone. The mRNAs of two water transporters, AQP1 and AQP4, were expressed in the bile duct cells. AQP8 mRNA was expressed in both bile duct cells and hepatocytes, and AQP9 mRNA was almost exclusively expressed in hepatocytes (Fig. 5C). Interestingly, cultured hepatocytes aberrantly expressed mRNAs for both AQP4 and AQP1, and transient treatment with dexamethasone suppressed the expression of AQP4 and stimulated the expression of AQP1 (Fig. 5C). In contrast, the expression of AQP9 mRNA was markedly decreased in cultured hepatocytes (Fig. 5C).

\section{The JNK-c-Jun pathway is activated by TNF- $\alpha$ in cultured hepatocytes}


To estimate the signaling pathways involved in the bile ductular transdifferentiation of hepatocytes, we examined the phosphorylation status of the major signaling molecules by Western blot analysis using phospho-specific antibodies. The phosphorylation of ERK and Akt was increased in cultured hepatocytes, while the phosphorylation of p38 MAPK was decreased and that of Stat3 and NFkB was almost unchanged (Fig. 6A). TNF- $\alpha$ did not affect the phosphorylation levels of these molecules (Fig. 6A). There was marked phosphorylation of JNK in freshly isolated hepatocytes and transient phosphorylation of c-Jun in hepatocytic spheroids (Fig. 6A), probably reflecting cellular stress during the isolation steps. The phosphorylation of JNK and c-Jun was increased during collagen gel culture, and it was further enhanced by TNF- $\alpha$ (Fig. 6A), suggesting a role of the JNK-c-Jun pathway in the TNF- $\alpha$-induced phenotypic change of hepatocytes. Immunocytochemical analysis for phosphorylated c-Jun demonstrated that the number and intensity of nuclear positivity of hepatocytes were increased by TNF- $\alpha$ treatment (Fig. 6B). After 14 days within the collagen gel, $32 \%$ of TNF- $\alpha$-treated cells were positive, while $13 \%$ of control cells were positive, for nuclear phosphorylated c-Jun.

To examine whether ductular reaction in vivo is associated with the activation of the JNK-c-Jun pathway, we performed an immunohistochemical study to assess the phosphorylation status of c-Jun in chronic liver disease induced by $\mathrm{CCl}_{4}$. In the control liver, there was no nuclear staining of phosphorylated c-Jun in hepatocytes, although their cytoplasm was faintly positive (Fig. 6 C, D). Less than $1 \%(0.9 \pm 0.3 \%$ [SEM], $n=4)$ of the nuclei of bile ducts were positive in the control liver (Fig. 6C, D). In the $\mathrm{CCl}_{4}$-induced 
cirrhotic liver, some of the regenerating hepatocytes $(7.6 \pm 2.8 \%[\mathrm{SEM}], \mathrm{n}=4)$ in the damaged centrilobular region demonstrated strong nuclear staining (Fig. 6C, D). The liver damage induced marked ductular reaction with significantly increased nuclear immunolabeling $(24.5 \pm 2.7 \%$ [SEM], $n=4)$ (Fig. 6C, D). These results suggest that the activation of the JNK-c-Jun pathway takes place during ductular reaction.

Next, we examined the effect of a JNK inhibitor, SP600125, on the TNF- $\alpha$-induced ductular morphogenesis. SP600125 suppressed the extent of branching morphogenesis in a concentration-dependent manner (Fig. 7A), supporting the hypothesized involvement of the JNK-c-Jun pathway in the ductular morphogenesis of hepatocytes. Western blot analysis confirmed that SP600125 suppressed TNF- $\alpha$-induced phosphorylation of c-Jun, but the inhibitor did not affect the expression of albumin, HNF-4a, and CK 19 (Fig. 7B). SP600125 did not induce cell death (Fig. 7A) or affected the levels of PCNA expression, which was augmented by TNF- $\alpha$ (Fig. 7B), suggesting that the inhibitory effect of the JNK inhibitor on branching morphogenesis could not be ascribed to increased cell death or suppression of cell proliferation.

\section{Discussion}

In this paper, we demonstrated that, among the Kupffer cell-derived cytokines, TNF- $\alpha$ strongly induced the bile ductular transdifferentiation of hepatocytes within a collagen gel matrix. Our results indicate that TNF- $\alpha$ also has a profound influence on the differentiation status of hepatocytes. While TNF- $\alpha$ has been implicated in the activation of inflammatory 
reactions and the aggravation of liver injury (Bradham et al., 1998; Tacke et al., 2009), our results suggest that its direct effects on hepatocyte differentiation might be involved in the pathogenesis of hepatic dysfunction characteristic of the chronic liver injury associated with fibrosis.

We observed that the ductular cells induced by TNF- $\alpha$ expressed several functional markers of bile ductules, such as CFTR and bile duct-specific aquaporins (AQP1, AQP4), and responded to secretin, further confirming that mature hepatocytes can transdifferentiate into bile ductular cells in vitro. Interestingly, AQP1 is expressed in intermediate hepatocytes and putative hepatic progenitor cells in human cirrhotic liver (Xian et al., 2009). The expression of secretin receptors has been demonstrated in the bile ductular cells appeared in $\mathrm{CCl}_{4}$-induced chronic liver injury in rats (LeSage et al., 1999). We also found that secretin receptor mRNA was highly expressed in hepatocytes cultured within the collagen gel in the presence of TNF- $\alpha$ (Sone et al., 2012).

The activity of TNF- $\alpha$ during liver regeneration is thought be mediated by the IL-6/STAT3 signaling pathway. The inhibition of liver regeneration in the TNFR1 knockout mice could be rescued by administration of IL-6 (Yamada et al., 1997). However, in our study there were striking differences between TNF- $\alpha$ and IL- 6 in terms of their effects on hepatocyte differentiation, as illustrated by the effects on morphogenesis and albumin expression monitored by DsRed 2 fluorescence. Furthermore, IL- $1 \alpha$ and IL-1 $\beta$ did not induce branching morphogenesis and only slightly affected albumin expression in culture. Our results are unexpected because these inflammatory cytokines have been shown to inhibit albumin 
expression in hepatocytes in conventional monolayer cultures (Dean et al., 2010). Although the reason for this discrepancy is not clear, it may reflect differences in culture conditions, which, in our case, three-dimensional collagen gel culture of aggregated hepatocytes in the presence of serum. Our data clearly show that the inflammatory cytokines exert distinct effects on hepatocyte differentiation, indicating that TNF- $\alpha$ is unique among these cytokines in its ability to suppress the hepatocytic phenotype.

TNF- $\alpha$ stimulates several signaling pathways, including the NF- $\kappa$ B and JNK-c-Jun pathways (Wullaert et al., 2007). In transdifferentiated hepatocytes induced by TNF- $\alpha$, there was an increase in the phosphorylation of JNK and c-Jun, but the phosphorylation of NF- $\mathrm{KB}$ was almost unchanged. The experiments using the specific JNK inhibitor (SP600125) suggested that the JNK-c-Jun pathway might be involved in branching morphogenesis. Since this pathway could also be activated by other inflammatory cytokines (IL-6, IL-1 $\alpha$, and IL-1 $\beta$ ) that did not induce ductular morphogenesis, the activation should be considered as a necessary condition, rather than a sufficient condition for ductular morphogenesis. The JNK-c-Jun pathway is involved in cell movement, actin cytoskeleton rearrangement, and morphogenesis in Drosophila and mice (Xia and Karin, 2004). Recently, this pathway has been shown to regulate tricellulin-mediated tight junctions in human pancreatic duct epithelial cells (Kojima et al., 2010), suggesting that it plays a critical role in ductular differentiation . In our study, however, the JNK inhibitor did not reverse the suppression of albumin expression. TNF- $\alpha$ has been reported to inhibit albumin production by phosphorylation and the nuclear export of $\mathrm{C} / \mathrm{EBP} \beta$, which is required for albumin gene transcription (Buck et al., 2001). Although these 
$\mathrm{C} / \mathrm{EBP} \beta$ alterations and albumin gene suppression by TNF- $\alpha$ can be reversed with antioxidants or inhibitors of nitric oxide synthases (Buck et al., 2001), treatment with these agents did not affect albumin expression in hepatocytes cultured in a collagen gel (data not shown), suggesting the involvement of other mechanisms in the suppression of albumin expression.

The production of TNF- $\alpha$ increases in liver diseases (Bradham et al., 1998) and may cause hepatocyte cell death rather than cell proliferation (Wullaert et al., 2007). Etanercept, an anti-TNF- $\alpha$ fusion protein, has been shown to improve virological response in interferon and ribavirin therapy in patients with chronic hepatitis $\mathrm{C}$ virus infection, without worsening liver histological responses (Yamaguchi et al., 2009). Our study raises the intriguing possibility that TNF- $\alpha$ could have important roles in ductular reaction via enhancing the ductular transdifferentiation of hepatocytes. Detection of nuclear phospho-c-Jun in ductular reaction, as well as in some of regenerating hepatocytes, induced by chronic treatment with $\mathrm{CCl}_{4}$ would imply that the activation of the JNK-c-Jun pathway, possibly through TNF- $\alpha$, might be operative in vivo. In chronic liver diseases, suppression of TNF- $\alpha$ activity might be beneficial for preventing the ductular transdifferentiation of hepatocytes, as well as for inhibiting inflammatory processes.

In conclusion, we have shown that, within a collagen-rich matrix, TNF- $\alpha$ strongly enhances the bile ductular transdifferentiation of hepatocytes, especially through the suppression of hepatocytic differentiation and enhancement of ductular morphogenesis. Recently, we also have observed phenotypic reversion of transdifferentiated ductular cells to 
mature hepatocytes when cells are retrieved from the collagen gel matrix and cultured serum-free on Matrigel in the presence of IL-6 or oncostatin M (Sone et al., 2012). These results suggest that there might be phenotypic plasticity between hepatocytes and bile ductular cells in the adult liver, depending on the microenvironment into which they are placed (Fig. 8). This hypothesis has therapeutic implications; the degradation of the collagenous matrix and the inactivation of Kupffer cells and HSCs might prevent or reverse the ductular transdifferentiation of hepatocytes in chronic liver diseases.

\section{Acknowledgments}

This work was supported in part by grants from the Ministry of Education, Culture, Sports, Science and Technology of Japan (\#13670204, \#16590303, and \#18590362). We thank Eiji Kobayashi for generously providing the Alb-DsRed2 transgenic rats and Yasuharu Ueno for helpful suggestions regarding the genotyping of the transgenic rats. We appreciate the excellent technical assistance of Akiko Yagisawa, Reiko Ito, Makiko Kawamata, Yoko Okada, and Ema Yamatomi. 


\section{References}

Alvaro D, Mancino MG, Glaser S, Gaudio E, Marzioni M, Francis H, Alpini G. 2007. Proliferating cholangiocytes: a neuroendocrine compartment in the diseased liver. Gastroenterology 132:415-431.

Bahcecioglu IH, Koca SS, Poyrazoglu OK, Yalniz M, Ozercan IH, Ustundag B, Sahin K, Dagli AF, Isik A. 2008. Hepatoprotective effect of infliximab, an anti-TNF-alpha agent, on carbon tetrachloride-induced hepatic fibrosis. Inflammation 31:215-221.

Block GD, Locker J, Bowen WC, Petersen BE, Katyal S, Strom SC, Riley T, Howard TA, Michalopoulos GK. 1996. Population expansion, clonal growth, and specific differentiation patterns in primary cultures of hepatocytes induced by HGF/SF, EGF and TGF alpha in a chemically defined (HGM) medium. J Cell Biol 132:1133-1149.

Bradham CA, Plumpe J, Manns MP, Brenner DA, Trautwein C. 1998. Mechanisms of hepatic toxicity. I. TNF-induced liver injury. Am J Physiol 275:G387-392.

Brenner DA, Buck M, Feitelberg SP, Chojkier M. 1990. Tumor necrosis factor-alpha inhibits albumin gene expression in a murine model of cachexia. J Clin Invest 85:248-255.

Buck M, Zhang L, Halasz NA, Hunter T, Chojkier M. 2001. Nuclear export of phosphorylated C/EBPbeta mediates the inhibition of albumin expression by TNF-alpha. Embo J 20:6712-6723.

Clotman F, Lannoy VJ, Reber M, Cereghini S, Cassiman D, Jacquemin P, Roskams T, Rousseau GG, Lemaigre FP. 2002. The onecut transcription factor HNF6 is required 
for normal development of the biliary tract. Development 129:1819-1828.

Clouston AD, Powell EE, Walsh MJ, Richardson MM, Demetris AJ, Jonsson JR. 2005.

Fibrosis correlates with a ductular reaction in hepatitis C: roles of impaired replication, progenitor cells and steatosis. Hepatology 41:809-818.

Dean S, Tang JI, Seckl JR, Nyirenda MJ. 2010. Developmental and tissue-specific regulation of hepatocyte nuclear factor 4-alpha (HNF4-alpha) isoforms in rodents. Gene Expr 14:337-344.

Desmet V, Roskams T, Van Eyken P. 1995. Ductular reaction in the liver. Pathol Res Pract 191:513-524.

Diehl AM, Yin M, Fleckenstein J, Yang SQ, Lin HZ, Brenner DA, Westwick J, Bagby G, Nelson S. 1994. Tumor necrosis factor-alpha induces c-jun during the regenerative response to liver injury. Am J Physiol 267:G552-561.

Iimuro Y, Gallucci RM, Luster MI, Kono H, Thurman RG. 1997. Antibodies to tumor necrosis factor alfa attenuate hepatic necrosis and inflammation caused by chronic exposure to ethanol in the rat. Hepatology 26:1530-1537.

Ito A, Nishikawa Y, Ohnuma K, Ohnuma I, Koma Y, Sato A, Enomoto K, Tsujimura T, Yokozaki H. 2007. SgIGSF is a novel biliary-epithelial cell adhesion molecule mediating duct/ductule development. Hepatology 45:684-694.

Jakubowski A, Ambrose C, Parr M, Lincecum JM, Wang MZ, Zheng TS, Browning B, Michaelson JS, Baetscher M, Wang B, Bissell DM, Burkly LC. 2005. TWEAK induces liver progenitor cell proliferation. J Clin Invest 115:2330-2340. 
Kamiya A, Gonzalez FJ. 2004. TNF-alpha regulates mouse fetal hepatic maturation induced by oncostatin M and extracellular matrices. Hepatology 40:527-536.

Kojima T, Fuchimoto J, Yamaguchi H, Ito T, Takasawa A, Ninomiya T, Kikuchi S, Ogasawara N, Ohkuni T, Masaki T, Hirata K, Himi T, Sawada N. 2010. c-Jun $\mathrm{N}$-terminal kinase is largely involved in the regulation of tricellular tight junctions via tricellulin in human pancreatic duct epithelial cells. J Cell Physiol 225:720-733.

Leist M, Gantner F, Bohlinger I, Tiegs G, Germann PG, Wendel A. 1995. Tumor necrosis factor-induced hepatocyte apoptosis precedes liver failure in experimental murine shock models. Am J Pathol 146:1220-1234.

LeSage GD, Benedetti A, Glaser S, Marucci L, Tretjak Z, Caligiuri A, Rodgers R, Phinizy JL, Baiocchi L, Francis H, Lasater J, Ugili L, Alpini G. 1999. Acute carbon tetrachloride feeding selectively damages large, but not small, cholangiocytes from normal rat liver. Hepatology 29:307-319.

Li Z, Yang S, Lin H, Huang J, Watkins PA, Moser AB, Desimone C, Song XY, Diehl AM. 2003. Probiotics and antibodies to TNF inhibit inflammatory activity and improve nonalcoholic fatty liver disease. Hepatology 37:343-350.

Michalopoulos GK, Barua L, Bowen WC. 2005. Transdifferentiation of rat hepatocytes into biliary cells after bile duct ligation and toxic biliary injury. Hepatology 41:535-544. Michalopoulos GK, Bowen WC, Mule K, Lopez-Talavera JC, Mars W. 2002. Hepatocytes undergo phenotypic transformation to biliary epithelium in organoid cultures. Hepatology 36:278-283. 
Nishikawa Y, Doi Y, Watanabe H, Tokairin T, Omori Y, Su M, Yoshioka T, Enomoto K. 2005. Transdifferentiation of mature rat hepatocytes into bile duct-like cells in vitro. Am J Pathol 166:1077-1088.

Nishikawa Y, Tokusashi Y, Kadohama T, Nishimori H, Ogawa K. 1996. Hepatocytic cells form bile duct-like structures within a three-dimensional collagen gel matrix. Exp Cell Res 223:357-371.

Richardson MM, Jonsson JR, Powell EE, Brunt EM, Neuschwander-Tetri BA, Bhathal PS, Dixon JB, Weltman MD, Tilg H, Moschen AR, Purdie DM, Demetris AJ, Clouston AD. 2007. Progressive fibrosis in nonalcoholic steatohepatitis: association with altered regeneration and a ductular reaction. Gastroenterology 133:80-90.

Rolfe M, James NH, Roberts RA. 1997. Tumour necrosis factor alpha (TNF alpha) suppresses apoptosis and induces DNA synthesis in rodent hepatocytes: a mediator of the hepatocarcinogenicity of peroxisome proliferators? Carcinogenesis 18:2277-2280.

Roskams T. 2003. Progenitor cell involvement in cirrhotic human liver diseases: from controversy to consensus. J Hepatol 39:431-434.

Roskams TA, Theise ND, Balabaud C, Bhagat G, Bhathal PS, Bioulac-Sage P, Brunt EM, Crawford JM, Crosby HA, Desmet V, Finegold MJ, Geller SA, Gouw AS, Hytiroglou P, Knisely AS, Kojiro M, Lefkowitch JH, Nakanuma Y, Olynyk JK, Park YN, Portmann B, Saxena R, Scheuer PJ, Strain AJ, Thung SN, Wanless IR, West AB. 2004. Nomenclature of the finer branches of the biliary tree: canals, ductules, and ductular reactions in human livers. Hepatology 39:1739-1745. 
Sato Y, Igarashi Y, Hakamata Y, Murakami T, Kaneko T, Takahashi M, Seo N, Kobayashi E. 2003. Establishment of Alb-DsRed2 transgenic rat for liver regeneration research. Biochem Biophys Res Commun 311:478-481.

Sone M, Nishikawa Y, Nagahama Y, Kumagai E, Doi Y, Omori Y, Yoshioka T, Tokairin T, Yoshida M, Sugiyama T, Enomoto K. 2012. Recovery of mature hepatocytic phenotype following bile ductular transdifferentiation of rat hepatocytes in vitro. Am J Pathol (in press).

Tacke F, Luedde T, Trautwein C. 2009. Inflammatory pathways in liver homeostasis and liver injury. Clin Rev Allergy Immunol 36:4-12.

Tilg H, Kaser A, Moschen AR. 2006. How to modulate inflammatory cytokines in liver diseases. Liver Int 26:1029-1039.

Wullaert A, van Loo G, Heyninck K, Beyaert R. 2007. Hepatic tumor necrosis factor signaling and nuclear factor-kappaB: effects on liver homeostasis and beyond. Endocr Rev 28:365-386.

Xia Y, Karin M. 2004. The control of cell motility and epithelial morphogenesis by Jun kinases. Trends Cell Biol 14:94-101.

Xian ZH, Cong WM, Wang YH, Wang B, Wu MC. 2009. Expression and localization of aquaporin-1 in human cirrhotic liver. Pathol Res Pract 205:774-780.

Yamada Y, Fausto N. 1998. Deficient liver regeneration after carbon tetrachloride injury in mice lacking type 1 but not type 2 tumor necrosis factor receptor. Am J Pathol 152:1577-1589. 
Yamada Y, Kirillova I, Peschon JJ, Fausto N. 1997. Initiation of liver growth by tumor necrosis factor: deficient liver regeneration in mice lacking type I tumor necrosis factor receptor. Proc Natl Acad Sci U S A 94:1441-1446.

Yamada Y, Webber EM, Kirillova I, Peschon JJ, Fausto N. 1998. Analysis of liver regeneration in mice lacking type 1 or type 2 tumor necrosis factor receptor: requirement for type 1 but not type 2 receptor. Hepatology 28:959-970.

Yamaguchi M, Yahata T, Fujita K, Sakurada J, Hasegawa G, Umezu H, Naito M, Tanaka K. 2009. Extranodal Rosai-Dorfman disease involving bilateral ovaries in a patient with a ventriculoperitoneal shunt. J Obstet Gynaecol Res 35:1000-1003. 


\section{Figure legends}

Fig. 1 The effect of various cytokines on the branching morphogenesis and DsRed2 fluorescence of Alb-DsRed2 transgenic rat hepatocytes cultured in a collagen gel matrix. (A) Phase-contrast and DsRed2 fluorescence micrographs of hepatocytic spheroids before and after being embedded in a collagen gel. The spheroids were cultured on Primaria dishes in serum-free culture medium for 5 days. The collagen gel culture was continued for 14 days in the absence or presence of either IL- 6 or TNF- $\alpha(10 \mathrm{ng} / \mathrm{ml})$. (B) Time course of DsRed2 fluorescence intensity during collagen gel cultures. Spheroidal aggregates of DsRed2 hepatocytes were embedded in a collagen gel and cultured for 7 days in the absence or presence of $10 \mathrm{ng} / \mathrm{ml}$ of IL-6, IL-1 $\alpha$, IL-1 $\beta$, or TNF- $\alpha$. Fluorescence intensity was measured each day with a fluorescent plate reader. Data represent the average $\pm \mathrm{SE}$ for a representative experiment performed in triplicate of at least three independent experiments with equivalent results.

Fig. 2 Time course of the expression of various differentiation markers and adhesion molecules in Alb-DsRed2 transgenic rat hepatocytes cultured in a collagen gel matrix. (A) Western blot analysis. Protein was extracted from freshly isolated hepatocytes, hepatocytic spheroids cultured on Primaria dishes (for 3 or 5 days), and spheroids cultured in a collagen gel (for 2, 4, 7, or 14 days) and analyzed for the expression of albumin, HNF-4 $\alpha$, CK 8, CK 19, SgIGSF, occludin, ZO-1, integrin $\beta 1$, and $\beta$-actin by Western blotting. In addition to $\beta$-actin expression, integrin $\beta 1$ expression, which was relatively constant in 
cultured hepatocytes, was used to verify equal loading. (B) Quantitative analysis. The intensity of signals ( $\%$ of maximum expression in a blot) for albumin, HNF- $4 \alpha, \mathrm{CK} 8$, and CK 19 was determined by densitometric evaluation in Western blots from four independent experiments. Each point shows the mean \pm SEM. $\uparrow \mathrm{p}<0.05$; $\uparrow \uparrow \mathrm{p}<0.01 ; \dagger \uparrow \uparrow \mathrm{p}<0.001$, as compared with freshly isolated hepatocytes (Heps) (Student's $t$-test). ${ }^{*} \mathrm{p}<0.05,{ }^{* *} \mathrm{p}<0.01$, as compared with corresponding control (Student's t-test).

\section{Fig. 3 Quantitative RT-PCR analysis of mRNA expression of various genes in} hepatocytes cultured in a collagen gel matrix. Expression of albumin, TAT, HNF-4 $\alpha, \mathrm{CK}$ 19, HNF-6, and PGC-1. Total RNA was extracted from freshly isolated hepatocytes, hepatocytic spheroids cultured on Primaria dishes (for 3 or 5 days), and spheroids cultured in a collagen gel (for 4, 7, or 14 days) and analyzed by quantitative RT-PCR. The mRNA levels were normalized using GAPDH as a housekeeping gene and represented as $\%$ of maximum expression in each experiment. Each point shows the mean \pm SEM from four independent experiments. $\uparrow \mathrm{p}<0.05 ; \dagger+\mathrm{p}<0.01 ; \dagger \dagger \mathrm{p}<0.001$, as compared with freshly isolated hepatocytes (Heps) (Student's $t$-test). ${ }^{*} \mathrm{p}<0.05$, as compared with corresponding control (Student's $t$-test).

\section{Fig. 4 Effect of TNF- $\alpha$ on the branching morphogenesis of hepatocytes in a collagen gel}

matrix. (A) Phase-contrast micrographs of hepatocytic spheroids cultured in a collagen gel for 2 to 21 days in the absence or presence of $10 \mathrm{ng} / \mathrm{ml}$ of TNF- $\alpha$. (B) Immunohistochemical 
observation for CK 19 and SgIGSF of the ductular structures formed in cells cultured in a collagen gel for 14 days in the absence or presence of $10 \mathrm{ng} / \mathrm{ml}$ of TNF- $\alpha$. Scale bars, $40 \mu \mathrm{m}$. (C) Electron micrographs of hepatocytic spheroids cultured in a collagen gel for 6 weeks in the presence of $10 \mathrm{ng} / \mathrm{ml}$ TNF- $\alpha$. The arrowheads in the left panel denote the basement membrane.

Fig. 5 Secretory functions of hepatocyte-derived ductules induced by TNF- $\alpha$ in a collagen gel matrix. (A) Uptake and excretion of fluorescein diacetate (FD) by the ductular structures cultured for 3 weeks in the presence of $10 \mathrm{ng} / \mathrm{ml}$ TNF- $\alpha$. The cells were treated with $1 \mu \mathrm{M}$ dexamethasone during the final week. (B) Phase-contrast micrographs taken before and 5 minutes after the addition of $2 \times 10^{-7} \mathrm{M}$ secretin. The arrowheads denote enlarged lumens following secretin treatment. (C) Gene expression (quantified by RT-PCR) of CFTR and various aquaporins (AQP) in hepatocytes, portal tract tissue, and hepatocytic spheroids cultured in collagen gel for 3 weeks in the absence or presence of $10 \mathrm{ng} / \mathrm{ml} \mathrm{TNF}-\alpha$ or $1 \mu \mathrm{M}$ dexamethasone (added after 2 weeks). The figure shows a representative experiment of four performed with similar results.

\section{Fig. 6 Activation of the JNK-c-Jun pathway in hepatocytes cultured in a collagen gel}

matrix. (A) Time course of the phosphorylation status of several signaling molecules in Alb-DsRed2 transgenic rat hepatocytes cultured in a collagen gel matrix. Protein was extracted from freshly isolated hepatocytes, hepatocytic spheroids cultured on Primaria dishes 
(for 3 or 5 days), and spheroids cultured in a collagen gel (for 2, 4, 7, or 14 days) and analyzed by Western blotting (applying blotted membranes equivalent to those used in Fig. 2). (B) Immunocytochemistry for phosphorylated c-Jun. Hepatocytic spheroids were cultured for 2 or 14 days in the absence or presence of $10 \mathrm{ng} / \mathrm{ml} \mathrm{TNF-} \alpha$. Scale bars, $20 \mu \mathrm{m}$. (C)

Immunohistochemistry for phosphorylated c-Jun in rat normal liver and $\mathrm{CCl}_{4}$-induced cirrhotic liver. Scale bars, $20 \mu \mathrm{m}$. (D) Quantitative analysis of phospho-c-Jun-positive nuclei in hepatocytes and bile duct/ductular cells in the normal and cirrhotic liver. Each point shows the mean \pm SEM from four independent experiments. ${ }^{*} \mathrm{p}<0.05 ; * * \mathrm{p}<0.01$, as compared with corresponding control (Student's t-test).

\section{Fig. 7 Effect of SP600125, a specific JNK inhibitor, on TNF- $\alpha$-induced branching} morphogenesis and hepatocytic differentiation and proliferation in a collagen gel matrix. (A) Effect of various concentrations of SP600125 (0-20 $\mu \mathrm{M})$ on branching morphogenesis of hepatocytic spheroids cultured for 14 days in the presence of $10 \mathrm{ng} / \mathrm{ml}$ TNF- $\alpha$. Phase-contrast micrographs. (B) Effect of SP600125 (0-40 $\mu \mathrm{M})$ on phosphorylation of c-Jun and the expression of albumin, HNF-4 $\alpha$, CK 19, PCNA, integrin $\beta 1$, and actin by Western blotting.

Fig. 8 Phenotypic transition between hepatocytes and bile ductules in response to the microenvironment (hypothesis). Hepatocytes undergo bile ductular transdifferentiation when cultured in a collagenous matrix. Our study shows that the transdifferentiation is markedly facilitated by TNF- $\alpha$ and suggests that the aberrant phenotype of hepatocytes may be at least 
partially reversible if the microenvironment is normalized. 
Figure 1 (Nishikawa et al.)

A

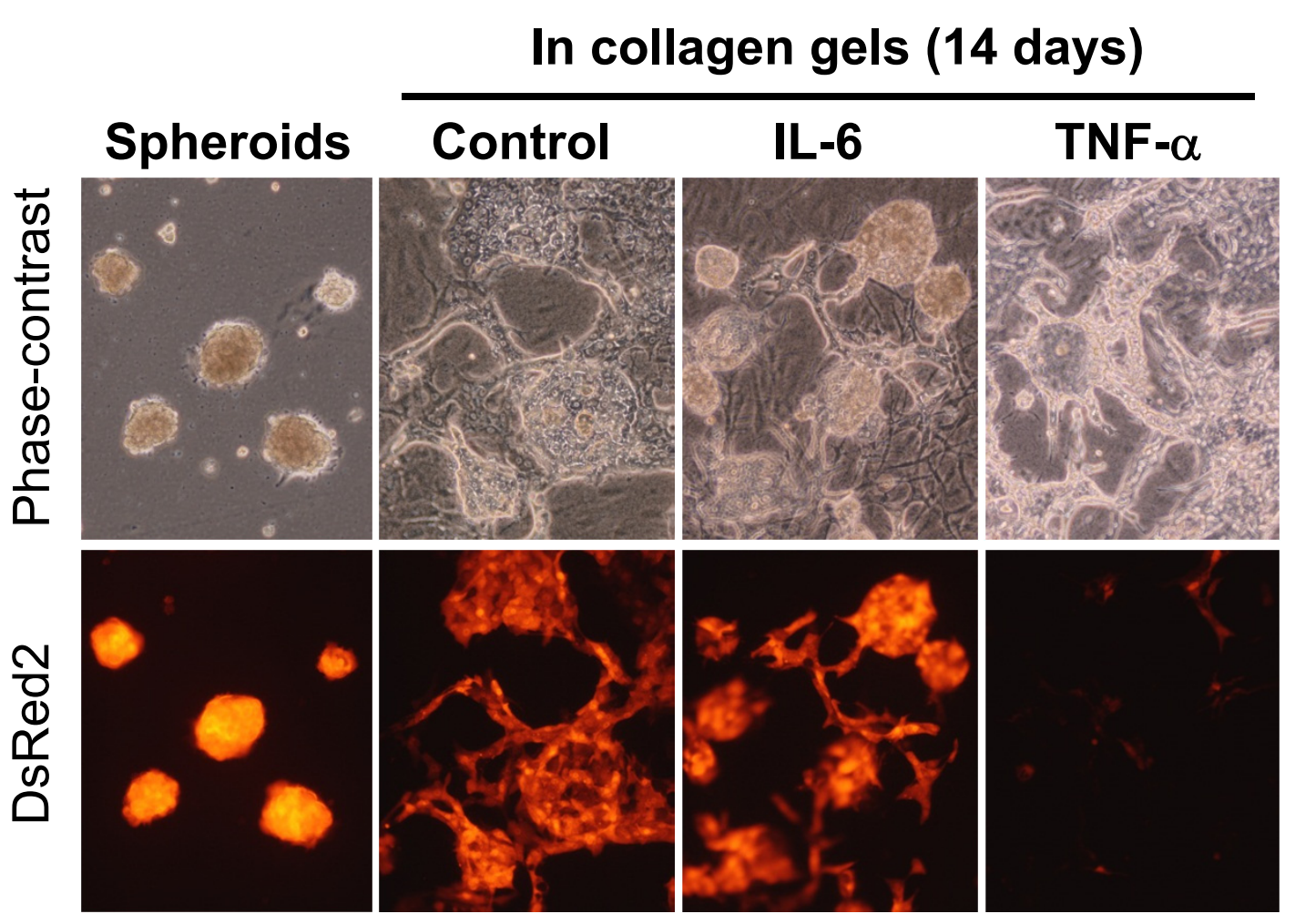

B




Figure 2 (Nishikawa et al.)

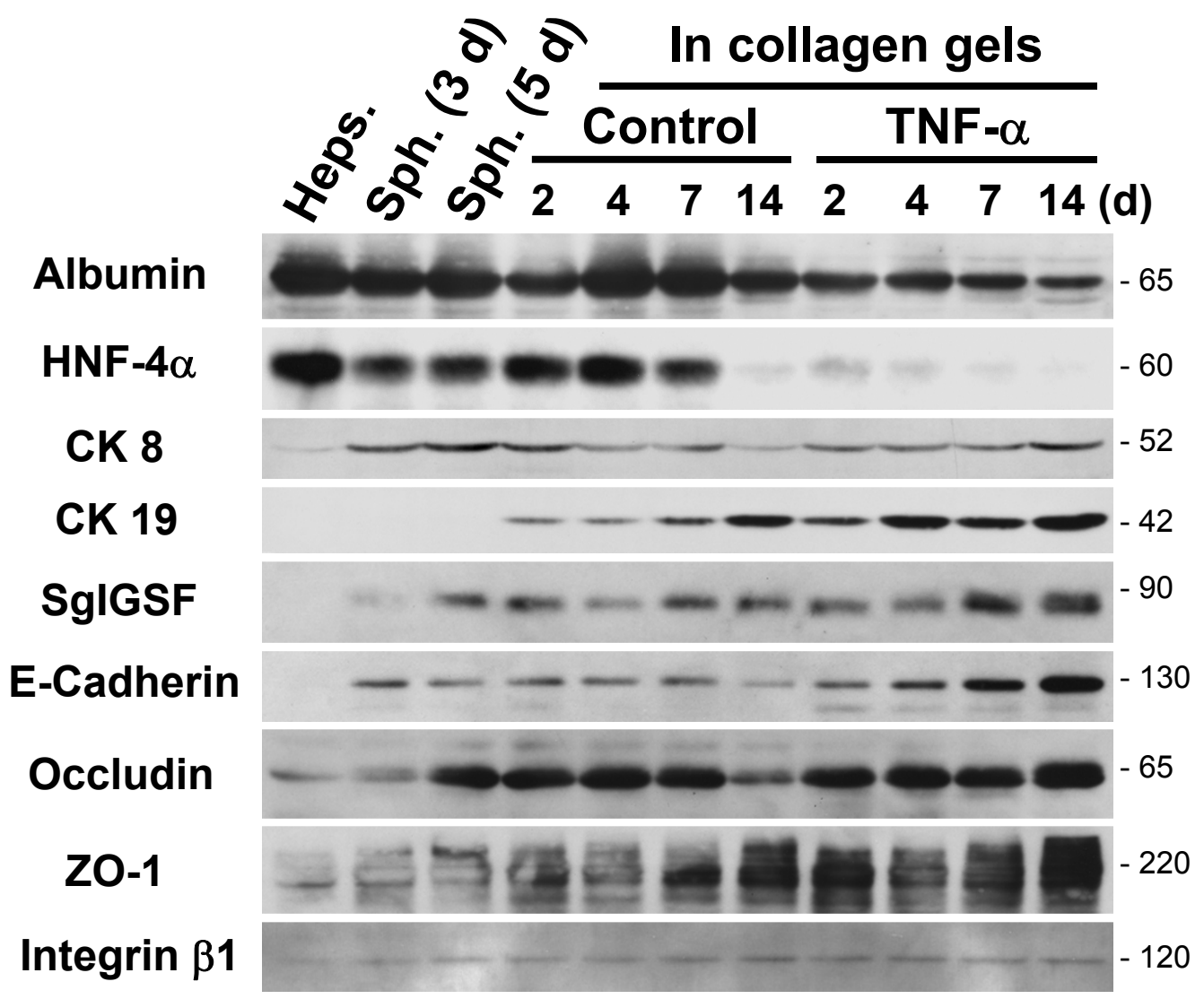


Figure 3 (Nishikawa et al.)

\section{Albumin}

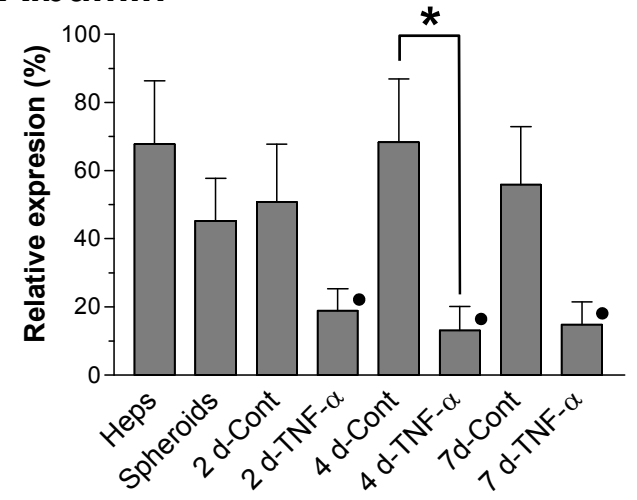

CK 8

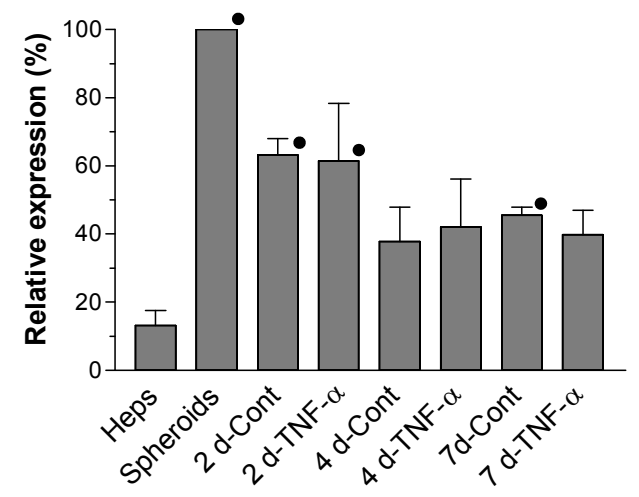

SgIGSF

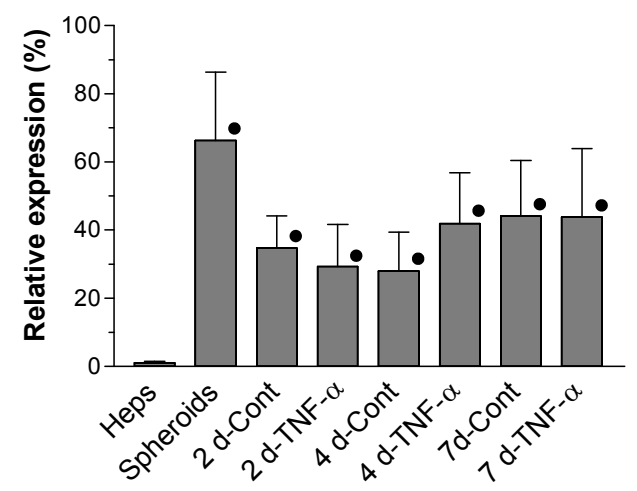

Occludin

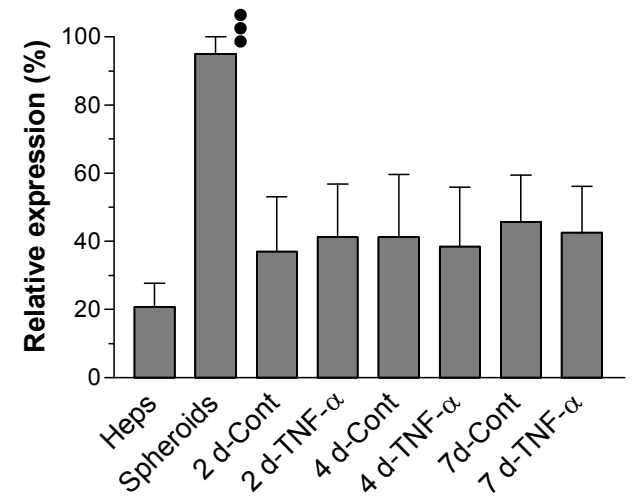

HNF-4 $\alpha$

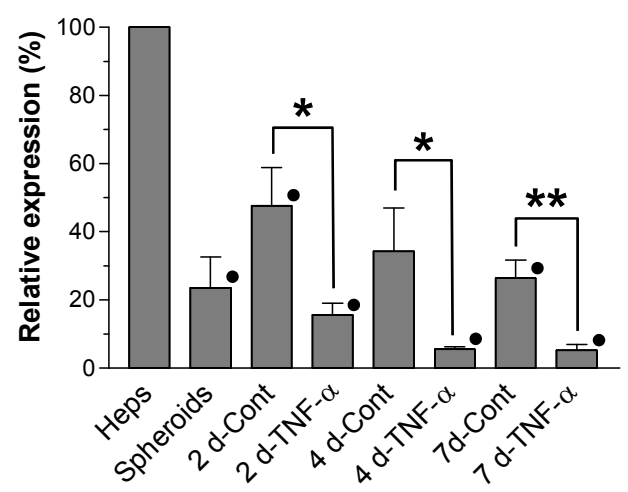

CK 19

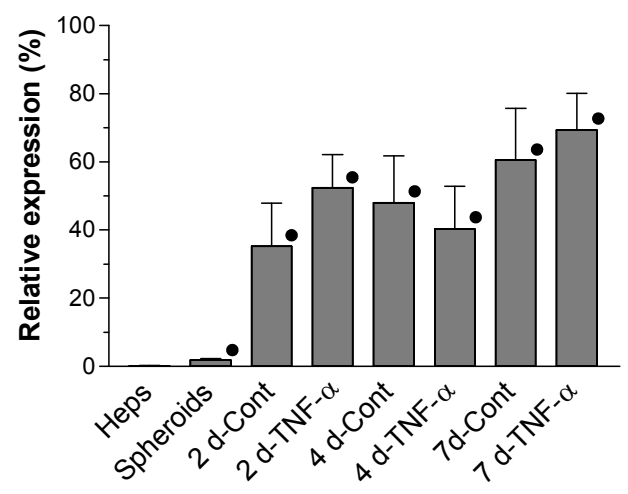

\section{E-cadherin}

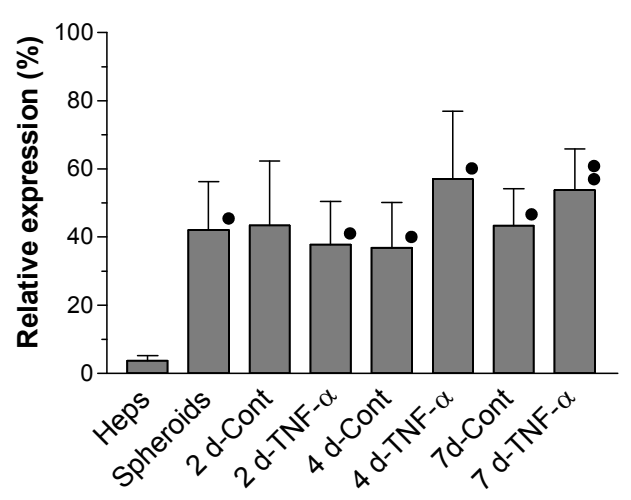

ZO-1

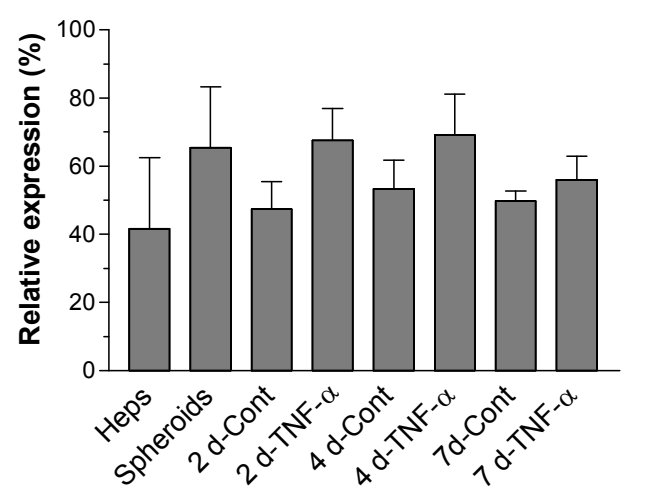


Figure 4 (Nishikawa et al.)

\section{Albumin}

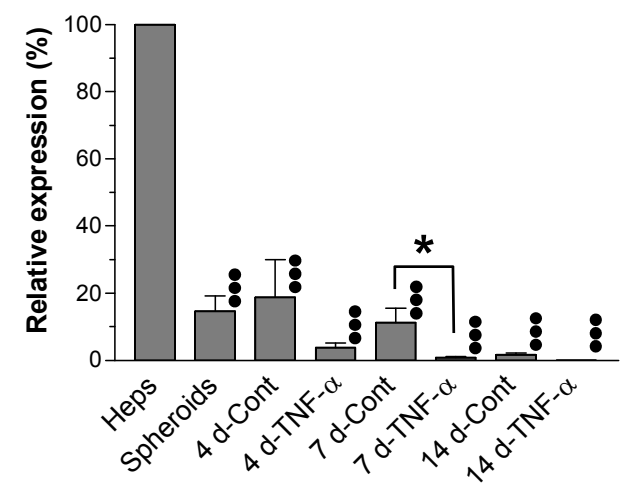

$H N F-4 \alpha$

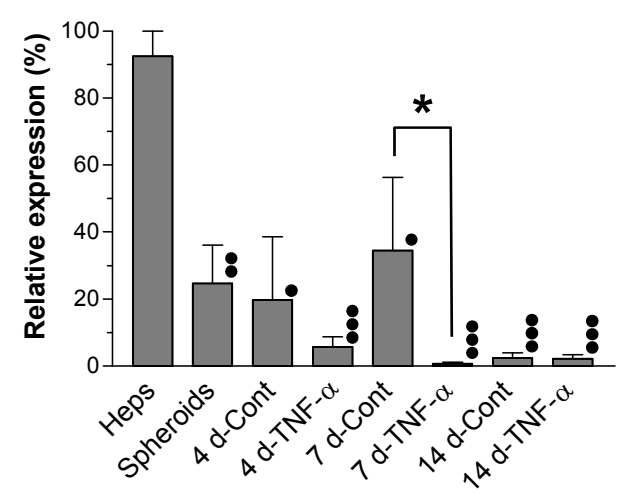

HNF-6

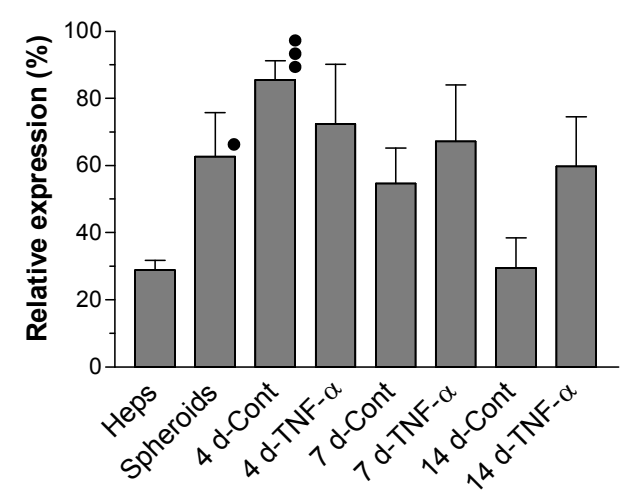

E-cadherin

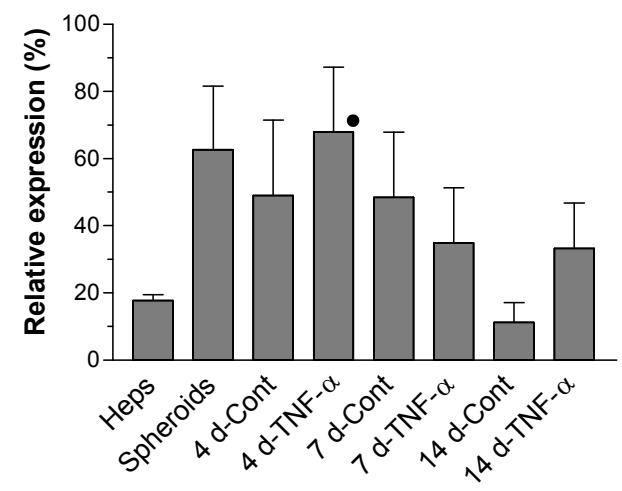

TAT


PGC-1

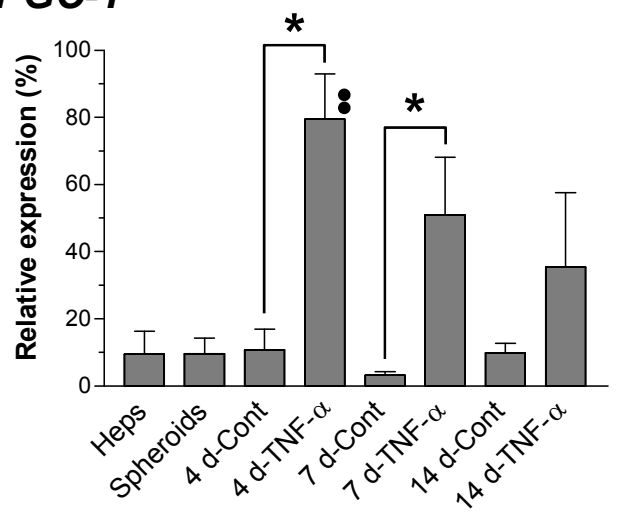

SDF-1

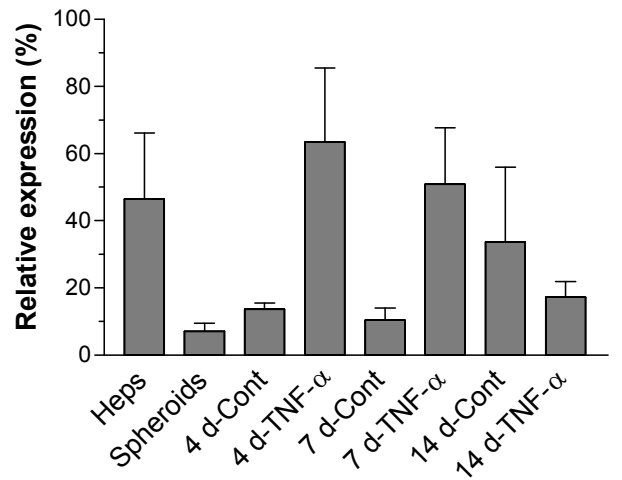


Figure 5 (Nishikawa et al.)


CK19

\section{SgIGSF}



C
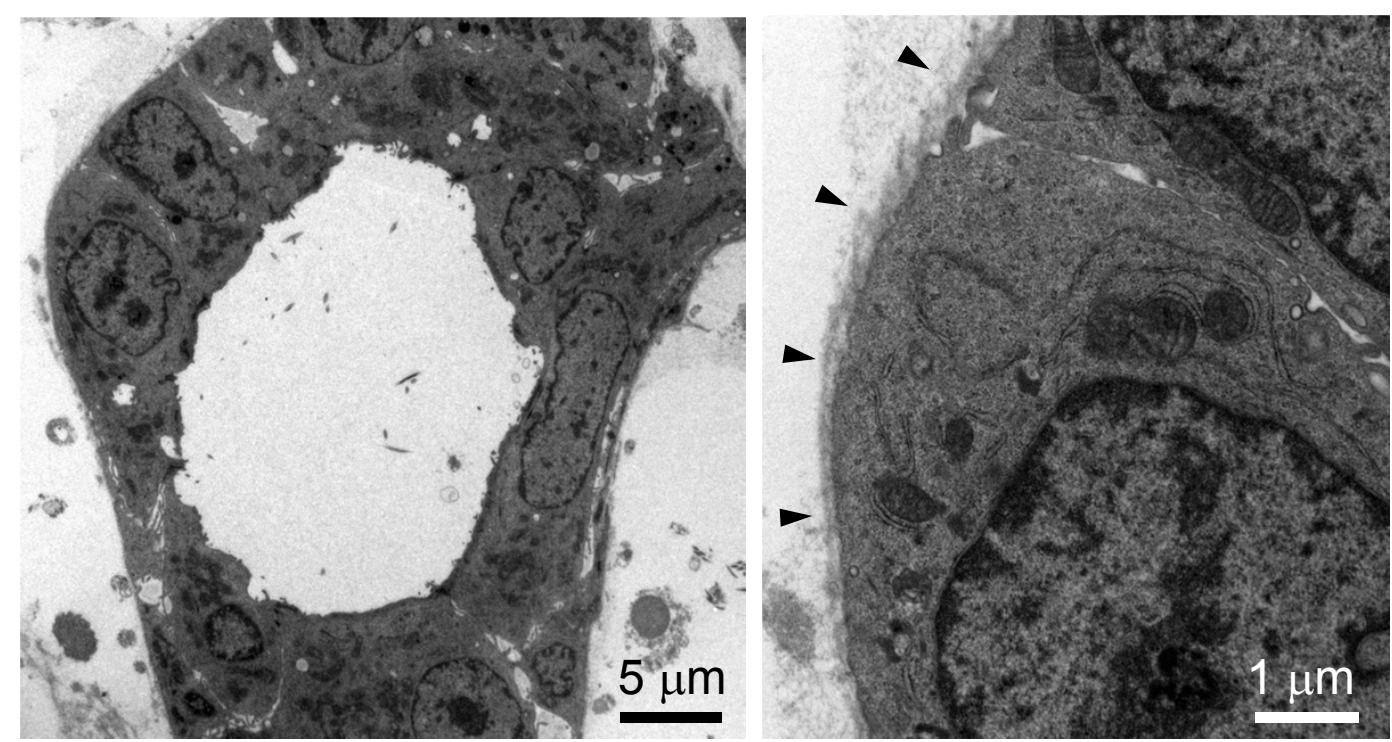
Figure 6 (Nishikawa et al.)

Figure 7 (Nishikawa et al.)

A

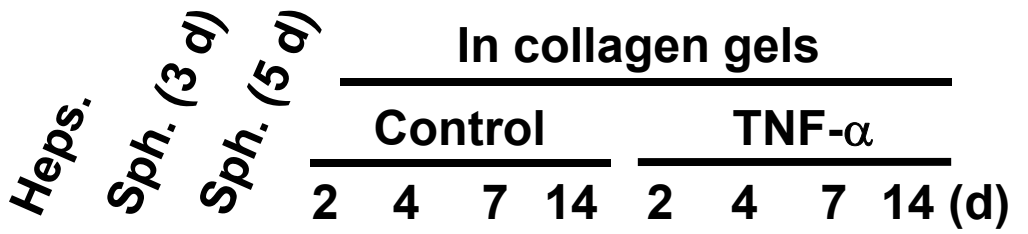

P-ERK

P-Akt

P-p38

P-Stat3

P-p65

P-JNK

P-c-Jun

Integrin $\beta 1$


B

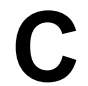

Control (2 d) TNF- $\alpha(2$ d) TNF- $\alpha(14$ d) P-C-Jun
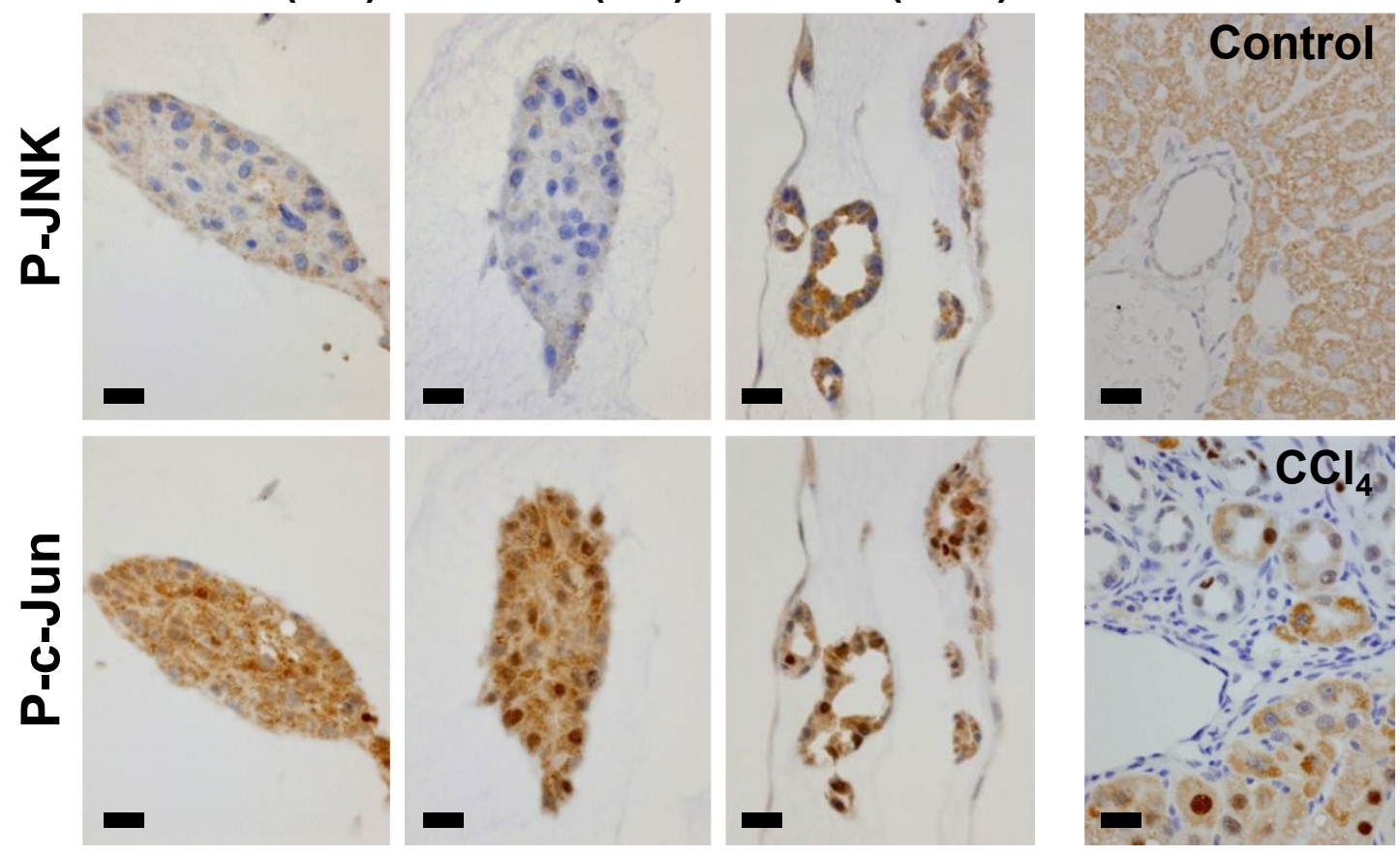
Figure 8 (Nishikawa et al.)
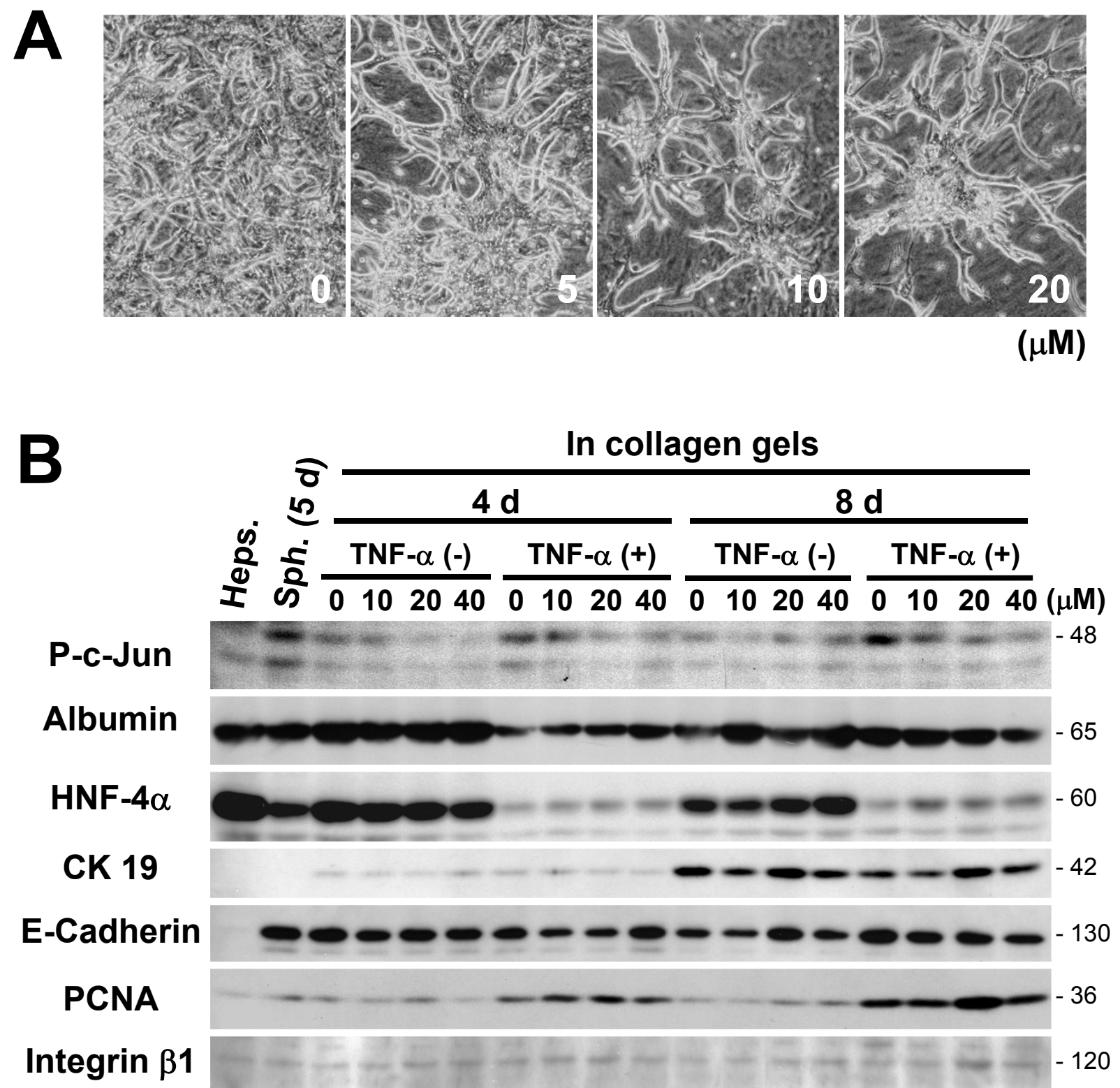
Figure 9 (Nishikawa et al.)



